\title{
Eruptive fracture location forecasts from high-frequency events on Piton de la Fournaise Volcano
}

\author{
Louis De Barros, ${ }^{1,2}$ Christopher J. Bean, ${ }^{1}$ Megan Zecevic, ${ }^{1}$ Florent Brenguier, ${ }^{3}$ \\ and Aline Peltier ${ }^{4}$ \\ Received 27 June 2013; revised 20 August 2013; accepted 20 August 2013; published 9 September 2013.
}

[1] Piton de la Fournaise (La Réunion island) is a very active basaltic volcano, with five eruptions between Nov 2009 and Dec 2010. Pre-eruptive seismic crises usually last for a few hours and mainly consist of a volcano-tectonic swarm. During the quiescent period between the volcanotectonic swarm and the eruptive tremor, we identify another swarm of events with a very high frequency content. These events are shallow and are located close to the future eruption site. They seem associated with the opening of the path for the magma propagating laterally at shallow depth. As these events start to occur while the magma is still in a vertical propagation phase, this seismicity seems to be related with the generic response of the volcano to the stress perturbation and not directly induced by the magma pressure. This new observation brings new insights to short-term forecasting of the eruption location. Citation: De Barros, L., C. J. Bean, M. Zecevic, F. Brenguier, and A. Peltier (2013), Eruptive fracture location forecasts from high-frequency events on Piton de la Fournaise Volcano, Geophys. Res. Lett., 40, 4599-4603, doi:10.1002/grl.50890.

\section{Introduction}

[2] Piton de la Fournaise (PdF) volcano is a hot-spot shield volcano located on La Réunion island in the Indian Ocean. This very active volcano erupted more than 30 times between 2000 and 2010 [Roult et al., 2012]. The eruptions are usually of short duration, lasting from a few hours to a few months and emit basaltic lava. Eruptions are either summital in the Dolomieu crater, proximal (on the flank of the central cone) or distal at more than $4 \mathrm{~km}$ from the summit [Peltier et al., 2009]. Since the end of 2009, the volcano is monitored by 21 broadband seismic stations (UNDERVOLC project; Brenguier et al. [2012]), which have recorded five eruptions (5 Nov 2009, 14 Dec 2009, 2 Jan 2010, 14 Oct 2010, and 9 Dec 2010).

\footnotetext{
Additional supporting information may be found in the online version of this article.

${ }^{1}$ School of Geological Sciences, University College Dublin, Dublin, Ireland.

${ }^{2}$ Géoazur, Université Nice Sophia Antipolis, CNRS, Observatoire de la Côte d'Azur, Sophia Antipolis, France.

${ }^{3}$ ISTerre, Université J. Fourier, CNRS, OSUG, Grenoble, France.

${ }^{4}$ Institut de Physique du Globe de Paris-Sorbonne Paris Cité, Université Paris Diderot, CNRS, Paris, France.
}

Corresponding author: L. De Barros, Géoazur, Université Nice Sophia Antipolis, CNRS, Observatoire de la Côte d'Azur, 250 rue Albert Einstein, Sophia Antipolis 06560, Valbonne, France. (debarros@geoazur.unice.fr)

(C)2013. American Geophysical Union. All Rights Reserved. 0094-8276/13/10.1002/grl.50890
[3] The pre-eruptive seismicity on Piton de la Fournaise is characterized by a dense swarm of volcano-tectonic (VT) events [Battaglia et al., 2005; Massin et al., 2011; Brenguier et al., 2012]. These events are mainly located around sea level, i.e., at about $2500 \mathrm{~m}$ below the summit. Several longperiod events sometimes occur toward the end of the seismic crisis, but only for proximal and distal eruptions [Aki and Ferrazzini, 2000; Zecevic et al., 2013]. These VT crises are followed by a period of pre-eruption quiescence, with a duration of several minutes or hours, which in turn are followed by the eruptive tremor accompanying the flow of lava. This simple and repetitive sequence of events exactly follows the general pre-eruptive pattern of seismicity described by McNutt [2005].

[4] The high resolution network of seismic stations, the frequent recurrence and the short time duration of eruptions, and the simplicity of the pre-eruptive patterns make this volcano an exceptional laboratory for developing new forecasting observations [e.g., Schmid et al., 2012]. We mainly focus here on the seismicity occurring before the proximal eruption on 14 Oct 2010. Interestingly, after the main seismic swarm of VT events, we identify a second swarm of events with a higher frequency content during the quiescence time at the stations, the closest to the eruptive vents. This paper aims to investigate the origin of these events and their potential for short-term forecasting of the location of lava extrusion.

\section{The 14 October 2010 Eruption}

[5] Since the end of 2009, the volcano has been monitored by 21 broadband seismic stations, including six 60 s Guralp CMG-3ESPC sensors and fifteen 30 s Guralp CMG-40T sensors (UNDERVOLC project; Brenguier et al. [2012]). All data used in this paper have been corrected for instrument response. The station distribution is exceptionally good with stations on the ridge of the main crater and an average distance of 1 to $2 \mathrm{~km}$ between stations.

[6] Figure 1 shows the seismic crisis recorded by two stations (U05 near the summit and FOR in the South, see Figure 2c). The main swarm of VT events started at 10:00 and lasted for less than $2 \mathrm{~h}$, after which a quiescence period of $3 \mathrm{~h}$ commenced. At 15:20, lava started to flow from a $150 \mathrm{~m}$ long fissure which opened South of the Dolomieu crater in the "Enclos Fouqué" (see Figure 2c and Roult et al. [2012]). The activity decreased after 17 Oct, and stopped on 31 Oct. This eruption is the first proximal eruption since the major eruption and crater collapse of 2007.

[7] For both stations, the seismic energy is very strong during the main VT swarm and the eruptive tremor episode. This energy is mainly present in a low-frequency range 
a)

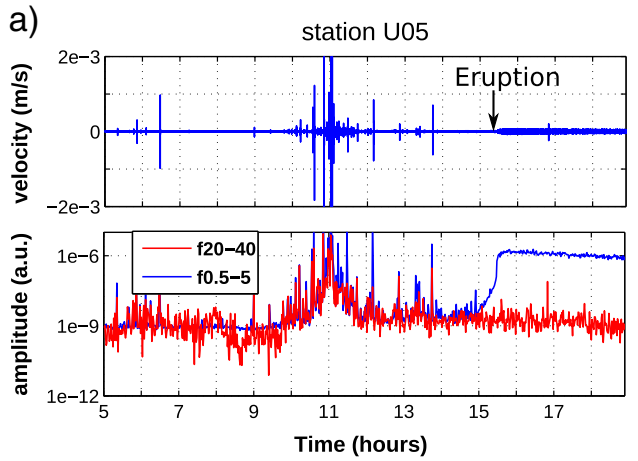

b)

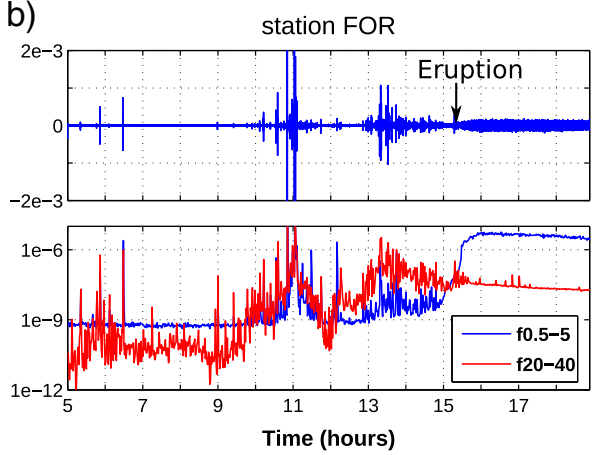

Figure 1. Vertical component of the pre-eruptive and initial eruption seismicity recorded on 14 Oct 2010 by stations (a) U05 and (b) FOR. The bottom panels show the seismic energy in two frequency bands $(0.5-5 \mathrm{~Hz}$ and $20-40 \mathrm{~Hz})$ for both stations. The vertical arrows show the beginning of the eruption.
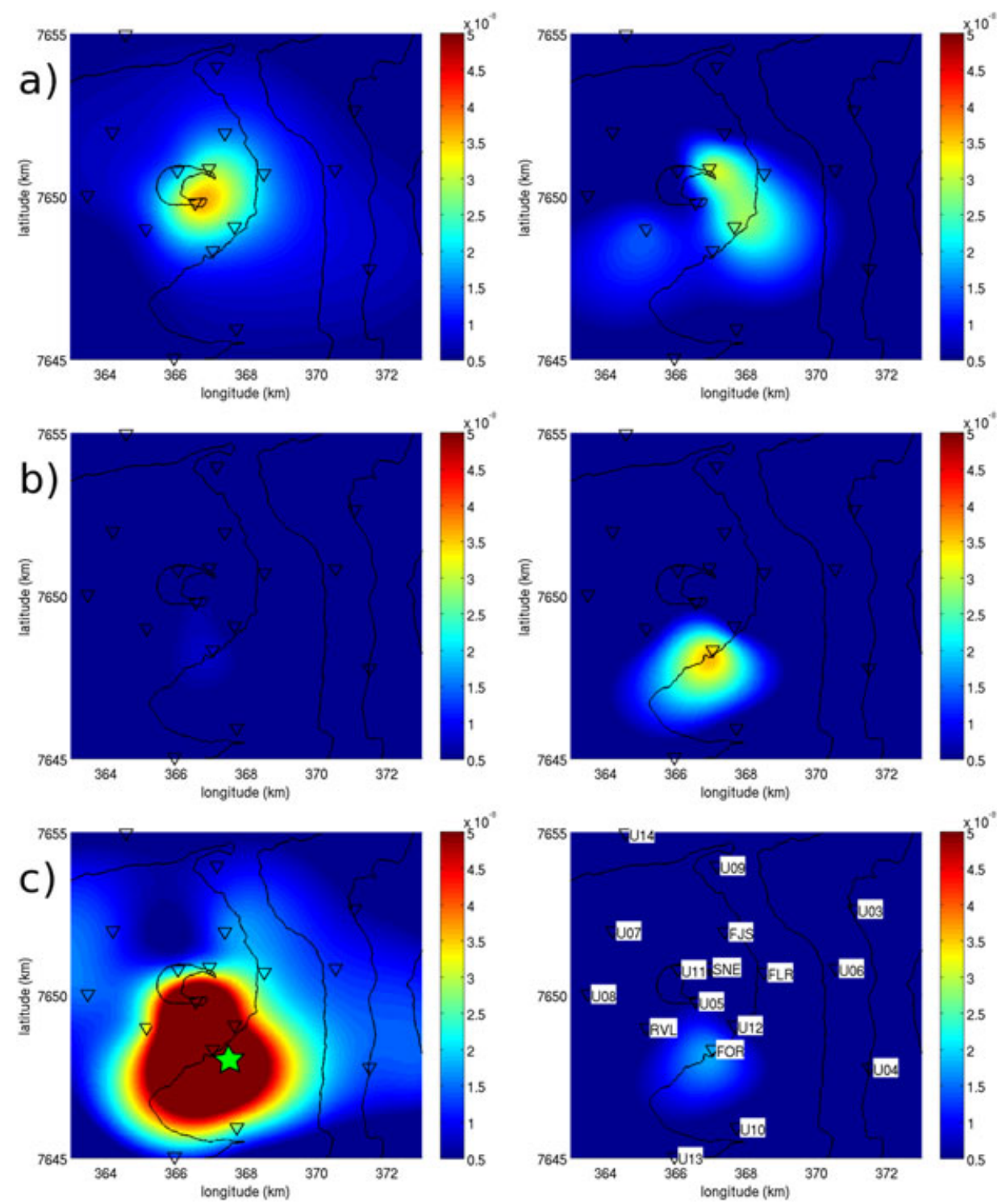

Figure 2. Five minutes root mean square amplitude interpolated between stations on the surface of the volcano in a (left) low-frequency band $(0.5-5 \mathrm{~Hz})$ and (right) high-frequency band $(20-40 \mathrm{~Hz})$ at three different periods: (a) Main seismic swarm (10:55), (b) high-frequency event swarm (13:49), and (c) beginning of the eruptive tremor (15:36). Elevation between contour lines is $500 \mathrm{~m}$. Triangles show the stations and the star indicate the eruptive vent location. Color scale (root mean square amplitude) is common for all the panels. See also Animation S2 in the supporting information. 

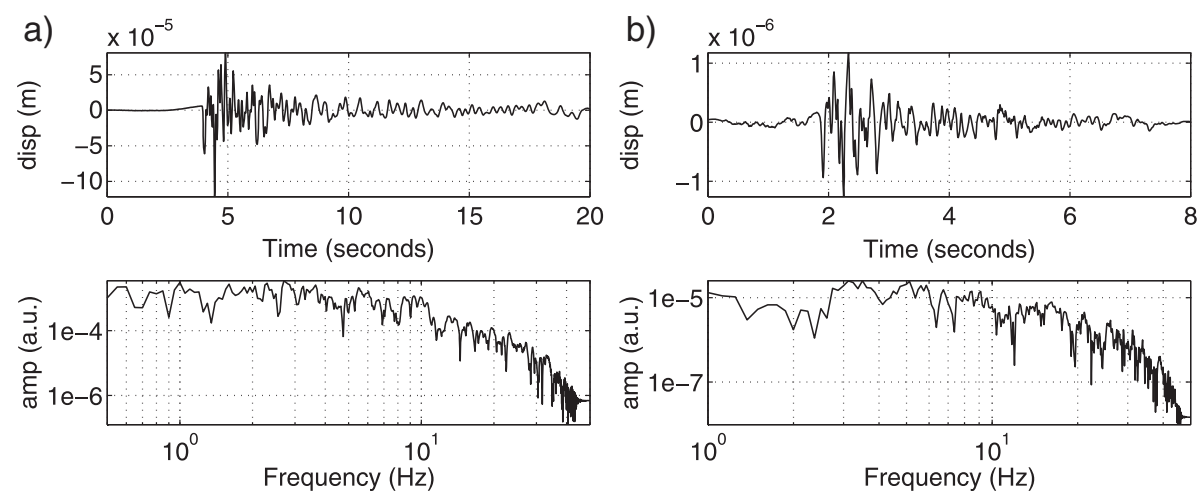

Figure 3. Seismic waveforms and spectra of (a) a VT event recorded during the main seismic crisis (11:02) and (b) a High-Frequency event (14:32). Both events are recorded at FOR station.

(i.e., less than $10 \mathrm{~Hz}$ ). While the quiescence period is almost free of visible events in the U05 data, a swarm of events can be seen at FOR station between 13:00 and 15:00. This swarm of events has a higher frequency content than the VT swarm. The energy of the signal filtered between 20 and $40 \mathrm{~Hz}$ clearly shows these events (see Figure 1). Herein we refer to the events forming this swarm as High-Frequency (HF) events.

\section{High-Frequency Events}

[8] Figure 3 shows a close-up of two events, one VT event recorded during the main seismic crisis and one HF event. They differ in their amplitudes ( 2 orders of magnitude) and their frequency content. The spectra of the VT and HF events show a classical earthquake pattern, with a corner frequency of $6 \mathrm{~Hz}$ and $14 \mathrm{~Hz}$, respectively. The HF events also seem to be volcano-tectonic (i.e., with a shear, brittle mechanism), but occur on smaller faults or smaller patches of faults.

[9] When looking at the waveforms recorded by different stations, the HF events can be seen at only four stations. Due to their low amplitude, the lowest frequencies of the signals are masked by noise at all stations. The high-frequency content, which is clearly visible in FOR data, is strongly scattered and attenuated, and subsequently cannot propagate very far from the source. It is therefore not possible to perform a quantitative location for these sources. In order to estimate the location qualitatively and to link the HF event with the other seismic signals, we interpolate the RMS amplitude onto the surface of PdF volcano [Battaglia and $A k i, 2003]$. This is achieved using a cubic interpolation of the cumulative RMS amplitude measured in 5 min windows filtered in a low-frequency band $(0.5-5 \mathrm{~Hz})$ and in a highfrequency band $(20-40 \mathrm{~Hz})$. Three snapshots are shown in Figure 2, corresponding to (1) the main VT swarm, (2) the HF swarm, and (3) the eruptive tremor periods. The Animation S2 (supporting information) shows the continuous distribution of the RMS amplitude in both frequency bands along the entire pre-eruptive sequence. The VT crisis is associated with high energy at both frequency bands, located at depth below the summit. High-frequency energy starts to appear south of the Dolomieu crater, and becomes progressively more visible during the quiescence period, which is dominated by the HF swarm. The eruptive tremor mainly contains low frequencies and also occurs in the south of the volcano around the eruptive vent. Unlike the VT seismicity, the HF events yield information on the future eruptive fracture location (see Figure 2) as their energy strongly decays with the offset from this area, where their epicenter seems to be located. Moreover, a deep source (i.e., at a depth greater than the interstation distance) would produce similar amplitudes on different stations. Hence, the sources of these events have to be shallow. This is supported by the bvalue in the Gutenberg-Richter law: a value of 0.9 and 1.55 is obtained for the VT swarm and HF swarm, respectively. This high value is a distinctive feature of events occurring in a low-stress environment [Schorlemmer et al., 2005], such as in the shallow subsurface of the volcano.

\section{Pre-eruptive Behavior}

[10] The HF swarm mainly differs from the VT swarm through its higher frequency content. Therefore, the ratio between the high-frequency and the low-frequency contents can be used to indicate the presence of HF events. Figure $4 \mathrm{~b}$ shows the cumulative ratio for all stations, computed on 5 min-long windows. As expected, this ratio is the highest in the stations for which high-frequency events can be seen and which surround the eruptive fracture. For those stations, this ratio starts to increase significantly at 10:00, i.e., during the main VT crisis and more than $5 \mathrm{~h}$ before the eruption onset. For the other eruptions in 2010 and 2011, the highest ratio is always observed at the stations that are the closest to the area where the eruption will occur a few hours later (see supporting Figure S1). This method can therefore be employed to forecast the location of the impending eruption.

[11] The average depth of the seismicity is derived using the seismic intensity ratio method described by Taisne et al. [2011]. In order to use waves propagating throughout the network and to consider the different types of events, we focus on the $5-15 \mathrm{~Hz}$ frequency band. We assume a $S$ wave velocity of $2 \mathrm{~km} / \mathrm{s}$ (consistent with Brenguier et al. [2007]). The seismicity first has deep and scattered source locations (around sea level), and then migrates toward the surface between 11:00 and 12:00, i.e., at the end of the VT crisis (Figure 4c). As usually observed on PdF [Peltier et al., 2009], the GPS data indicate a two-phase deformation, and GPS stations close to UV5 and FOR (Figure 2c) show different deformation patterns (Figure 4d). The dike first propagates vertically, leading to high deformation of the 
a)

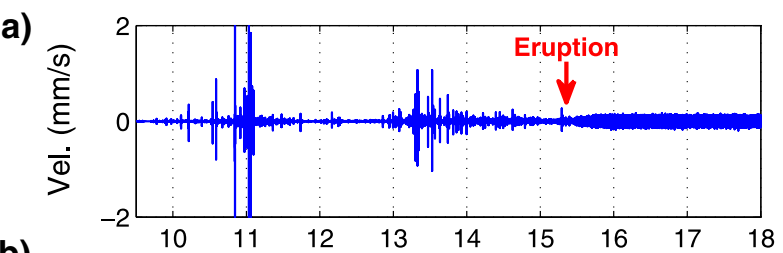

b)

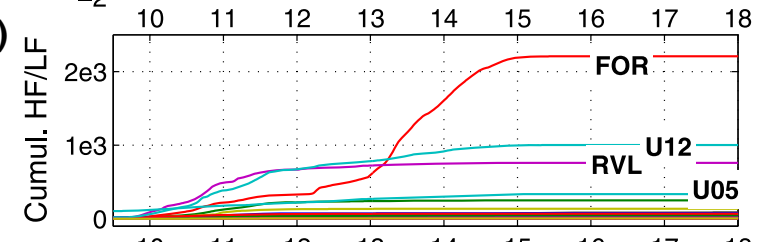

c)
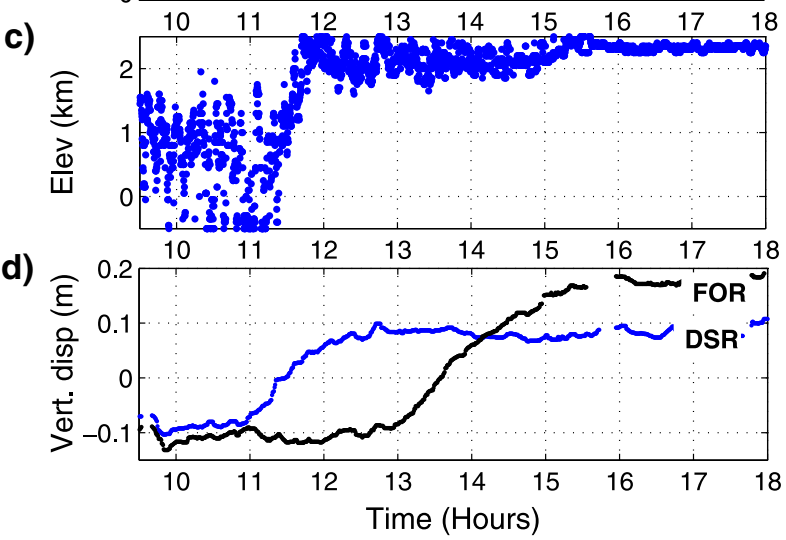

Figure 4. (a) Seismic activity before and during the beginning of the eruption on 14 Oct 2010 recorded by the FOR station. (b) Cumulative High Frequency $(20-40 \mathrm{~Hz}) / \mathrm{Low}$ Frequency $(0.5-5 \mathrm{~Hz})$ ratio for all stations. The four highest ratios are labeled with the corresponding station names. (c) Elevation of the seismicity sources using radiated seismic intensity. (d) Vertical deformation recorded by the GPS station DSR (close to U05) and FOR.

volcano summit between 10:55 and 12:00. From 11:30, the magma starts its lateral propagation toward the south, the deformation is localized only in the south of the volcano after 13:00.

[12] The different observations summarized in Figure 4 show the following: (1) The VT swarm occurred at the beginning of the vertical propagation of the magma. The vertical migration of the seismicity is associated with deformation localized on the summit; (2) During the lateral propagation of the dike, deformation and seismicity (HF events) are only recorded in the south of the volcano; (3) The $\mathrm{HF} / \mathrm{LF}$ ratio starts to increase in the south of the volcano toward the end of the VT swarm, i.e., when the dike is still in its vertical migration phase.

\section{Discussion and Conclusion}

[13] During the quiescence period occurring between the main seismic crisis and the eruption, we observe a second swarm of high-frequency events at some stations. This observation is rendered possible thanks to the highly dense seismic network deployed on the volcano. These events seem to be generated at very shallow depths compared to the classical VT events, which usually occur at depths greater than $1 \mathrm{~km}$ [Battaglia et al., 2005; Massin et al., 2011]. Using energy mapping, we determine that the HF events are located in the area of the eruptive fracture. As they have a high-frequency content, which is lacking in the VT events, high-to-low-frequency ratios allow us to track their evolution. Their high-frequency contents indicate failure on small faults (or small patches), with a diameter no greater than $60 \mathrm{~m}$ [Madariaga, 1976]. This is consistent with a shallow seismicity, as the near-surface cannot support large faults because of the topography and/or weak material properties. Therefore, the VT and HF in this study share a similar mechanism and belong to the same group of events.

[14] These HF events may have significant implications for monitoring purposes: monitoring the high-to-lowfrequency energy ratio during the main seismic crisis (i.e., a few hours before the eruption onset) allows for a forecast of the eruption location. This is confirmed here by computing this ratio for another proximal eruption (Dec 2010) and for summit eruptions (Nov 2009 and Jan 2010, see supporting information Figure S1). In every case, the largest frequency ratio before the eruption onset is obtained at the stations closest to the upcoming eruptions. This information can be coupled with the occurrence of Long-Period events, which is an indication of an eruption outside of the summit area on PdF [Aki and Ferrazzini, 2000; Zecevic et al., 2013].

[15] The VT and HF swarms are related to the vertical and lateral migration of the magma, respectively. However, the HF seismicity seems to start to occur during the VT swarm, i.e., when the magma is still in its vertically migrating phase at depth (c. $2 \mathrm{~km}$ below sea level) beneath the summit. The HF seismicity is therefore likely a generic response of the shallow part of the edifice to the stress changes due to the dike propagation [Traversa et al., 2010]. These failures are triggered indirectly by the stress induced by the magma movement, and not by the magma itself. As these shallow failures occur in the area of the eruption, they play a role in the process of dike propagation by creating the pathway along which the magma later propagates. The eruptive fissure might be exploiting a structural weakness which can be monitored through HF events. The shallow magma path and the eruption area are therefore already defined when the magma is still in its vertically migrating phase. Hence, the location of lava output can be forecast up to $3 \mathrm{~h}$ prior to the eruption.

[16] On Piton de la Fournaise, the pre-eruptive seismicity has a short time duration and is rather simple compared to other volcanoes. However, it follows the generic swarm pattern of McNutt [2005]. The observations made herein might therefore be reproduced on other volcanoes where the station distribution is sufficiently dense.

[17] Acknowledgments. The data used for the analysis were collected by the Institut de Physique du Globe de Paris, Observatoire Volcanologique du Piton de la Fournaise (IPGP/OVPF), and the Institut des Sciences de la Terre (ISTerre) within the framework of ANR_08_RISK_011/UnderVolc project. The sensors are property of the French transportable seismic network, Sismob (INSU-CNRS). We are grateful to V. Ferrazzini, T. Staudacher, and A. Di Muro for instructive discussions.

[18] The editor thanks an anonymous reviewer for his assistance in evaluating this paper.

\section{References}

Aki, K., and V. Ferrazzini (2000), Seismic monitoring and modeling of an active volcano for prediction, J. Geophys. Res., 105(B7), 16,617-16,640.

Battaglia, J., and K. Aki (2003), Location of seismic events and eruptive fissures on the Piton de la Fournaise volcano using seismic amplitudes, J. Geophys. Res., 108(B8), 2364, doi:10.1029/2002JB002193.

Battaglia, J., V. Ferrazzini, T. Staudacher, K. Aki, and J.-L. Cheminée (2005), Pre-eruptive migration of earthquakes at the Piton de la Fournaise volcano (Réunion island), Geophys. J. Int., 161(2), 549-558. 


\section{DE BARROS ET AL.: HIGH-FREQUENCY EVENTS ON PDF}

Brenguier, F., N. M. Shapiro, M. Campillo, A. Nercessian, and V. Ferrazzini (2007), 3-D surface wave tomography of the Piton de la Fournaise volcano using seismic noise correlations, Geophys. Res. Lett., 34, L02305, doi:10.1029/2006GL028586.

Brenguier, F., et al. (2012), First results from the UnderVolc high resolution seismic and GPS network deployed on Piton de la Fournaise volcano, Seismol. Res. Lett., 83(1), 97-102.

Madariaga, R. (1976), Dynamics of an expanding circular fault, Bull. Seismol. Soc. Am., 66(3), 639-666.

Massin, F., V. Ferrazzini, P. Bachlery, A. Nercessian, Z. Duputel, and T. Staudacher (2011), Structures and evolution of the plumbing system of Piton de la Fournaise volcano inferred from clustering of 2007 eruptive cycle seismicity, J. Volcanol. Geotherm. Res., 202(1-2), 96-106.

McNutt, S. R. (2005), Volcanic seismology, Annu. Rev. Earth Planet. Sci., 33(1), 461-491.

Peltier, A., P. Bachlery, and T. Staudacher (2009), Magma transport and storage at Piton de La Fournaise (la Réunion) between 1972 and 2007: A review of geophysical and geochemical data, J. Volcanol. Geotherm. Res., 184(1-2), 93-108.

Roult, G., A. Peltier, B. Taisne, T. Staudacher, V. Ferrazzini, and A. Di Muro (2012), A new comprehensive classification of the Piton de la Fournaise activity spanning the 1985-2010 period. Search and analysis of shortterm precursors from a broad-band seismological station, J. Volcanol. Geotherm. Res., 241-242, 78-104.

Schmid, A., J. R. Grasso, D. Clarke, V. Ferrazzini, P. Bachlery, and T. Staudacher (2012), Eruption forerunners from multiparameter monitoring and application for eruptions time predictability (Piton de la Fournaise), J. Geophys. Res., 117, B11203, doi:10.1029/ 2012JB009167.

Schorlemmer, D., S. Wiemer, and M. Wyss (2005), Variations in earthquake-size distribution across different stress regimes, Nature, 437(7058), 539-542.

Taisne, B., F. Brenguier, N. M. Shapiro, and V. Ferrazzini (2011), Imaging the dynamics of magma propagation using radiated seismic intensity, Geophys. Res. Lett., 38, L04304, doi:10.1029/2010GL046068.

Traversa, P., V. Pinel, and J. R. Grasso (2010), A constant influx model for dike propagation: Implications for magma reservoir dynamics, J. Geophys. Res., 115, B01201, doi:10.1029/2009JB006559.

Zecevic, M., L. De Barros, C. J. Bean, G. O’Brien, and F. Brenguier (2013), Investigating the source characteristics of long-period (LP) seismic events recorded on Piton de la Fournaise volcano, La Réunion, J. Volcanol. Geotherm. Res., 258, 1-11. 